\title{
Social signals and sustainability: Ambiguity about motivations can affect status perceptions of efficiency and
} curtailment behaviors

\author{
Matheus De Nardo ${ }^{1}$ \\ Jeremy S. Brooks ${ }^{1 *}$ \\ Sonja Klinsky ${ }^{2}$ \\ Charlie Wilson ${ }^{3}$
}

1. School of Environment and Natural Resources, The Ohio State University, 210 Kottman Hall, 2021 Coffey Rd. Columbus, OH 43210, USA: brooks.719@,osu.edu; 1-614-292-9787

2. Julie Ann Wrigley Global Institute of Sustainability, Arizona State University, PO Box 875502, Tempem AZ 85287.Sonja.Klinksky@asu.edu

3. Tyndall Center for Climate Change Research, University of East Anglia, Norwich NR4 7TJ, UK: charlie.wilson@uea.ac.uk

* Corresponding author

This study was determined to be exempt from IRB review by the Office of Responsible Research Practices at the Ohio State University (project number 2013E0189).

\begin{abstract}
Perceived status can affect the diffusion of pro-environmental behaviors and sustainable consumption. However, the status of different forms of sustainable consumption has not been adequately explored. Previous studies suggest that curtailment behaviors are associated with low or neutral status while efficiency behaviors are associated with high status. However, these studies have generally examined a small number of behaviors. Drawing from costly signaling theory we developed a mixed methods study to explore whether and why pro-environmental behaviors are perceived to be associated with high or low status, the perceived motivation for those behaviors, and the relationship between motivation and status. We conducted structured, interactive interviews with 71 participants to explore perceptions of 19 behaviors. Using quantitative and qualitative analyses, we find that efficiency is rated higher status than curtailment largely due to monetary considerations. Efficiency is also perceived to be motivated by environmental concern more so than curtailment. Understanding the motivation for behaviors clarifies the social signal because it provides insights into whether one is incurring personal costs. Importantly, it is often unclear whether low-cost curtailment behaviors are adopted by choice rather than financial need. Ambiguity about the intentionality of behaviors results in such behaviors being perceived as lower status. Those who argue that curtailment will be necessary for long-term sustainability must address status perceptions because social stigmas could hinder their adoption. Overcoming such stigmas may require indicating that curtailment behaviors are voluntary, but it may be more effective to use social or economic mechanisms to increase efficiency behaviors.
\end{abstract}

Keywords: Sustainable consumption; prosocial behavior; environmental motivation; pro-environmental behavior; overconsumption; diffusion 


\section{INTRODUCTION}

Recent studies have begun to examine the degree to which sustainable consumption is associated with higher social status (Brooks and Wilson, 2015; Delgado et al., 2015; Griskevicius et al., 2010; Zabkar and Hosta, 2013). While not all behaviors or purchases have clear status implications, the focus on status is important because both theory (Henrich and Gil-White, 2001; Richerson and Boyd, 2005) and empirical research (Cohen and Prinstein, 2006; Van den Bulte and Stremersch, 2004) suggest that individuals perceived as having higher status are evaluated more favorably and are more likely to be imitated (Hardy and van Vugt, 2006; Henrich and GilWhite, 2001). Thus, understanding whether and why particular behaviors and forms of consumption are associated with high status can provide insights into whether or not they are copied and become more widely adopted.

The recent studies noted above suggest that social status can be enhanced by efficiency behaviors (Griskevicius et al., 2010). Efficiency behaviors tend to entail relatively high monetary costs and the purchase of new, more efficient products rather than behavioral change (Jansson et al., 2010; Karlin et al., 2014) (see Table 1 for more detailed definitions of key terms). In contrast, there is little evidence that status is enhanced by curtailment behaviors (Brooks and Wilson, 2015; Welte and Anastasio, 2010), which generally have low, or no, monetary cost and focus on behavioral change rather than new technologies or purchases (see Table 1). In fact, such behaviors may be associated with low status (Sadalla and Krull, 1995).

Despite these differences, efficiency and curtailment can both be considered cooperative, prosocial behaviors because they involve personal costs (monetary for the former, non-monetary 
for the latter) for the provision of collective benefits in the form of lower environmental impacts (van Vugt et al., 2007). Importantly, prosocial behavior can also enhance status. Prosocial individuals are considered more trustworthy, more desirable as friends and allies, and are more likely to be elected as leaders (Gintis et al., 2001; Henrich, 2009; Willer, 2009). As such, we may act prosocially to gain social approval (Ariely et al., 2009). If both efficiency and curtailment can, in the abstract, be considered prosocial behavior, why might efficiency be associated with high status but not curtailment?

The premise of this study is that the degree to which behaviors are perceived as prosocial, and subsequently associated with high status, depends on the clarity of the social signal associated with that behavior. That is, it has to be clear that the behavior entails personal costs and collective benefits. Importantly, the degree to which these costs are clear can depend on the characteristics of the behavior itself as well as the context in which the behavior occurs (Brooks and Wilson, 2015). Curtailment behaviors may not be associated with high status to the same degree as efficiency behaviors because curtailment involves reductions in material consumption that could be perceived as being a necessity driven by low income as opposed to a choice driven by concern about the state of the environment. For example, choosing to ride the bus to reduce one's environmental impact could be considered prosocial, and thus status-worthy, but taking the bus out of financial necessity does not require additional personal costs motivated by environmental concern and so is unlikely to be considered costly or prosocial. Costly signaling theory provides important insights about the relationship between status, sustainable consumption, and proenvironmental behavior. 


\subsection{Status, consumption, and costly signaling}

The long history of exploring the relationship between status and consumption has often focused on wasteful, conspicuous consumption (e.g. Hirsch, 1976; Johansson-Stenman and Martinsson, 2006; Veblen, 1899). Conspicuous consumption can be explained by costly signaling theory, which suggests that particular behaviors or consumption patterns can act as cues that accurately and reliably signal underlying traits (Bliege Bird and Smith, 2005). Here, wealth is reliably signaled by the monetary cost of the product or behavior on display and this indication of wealth enhances ones status.

However, sustainable consumption can also signal one's ability to absorb the costs (whether monetary or non-monetary) that come with prosocial acts (van Vugt et al., 2007). For instance, owning a high efficiency vehicle could imply absorbing personal costs (less comfort and lower performance) for collective benefits (lower $\mathrm{CO}_{2}$ emissions). This might signal that one is more concerned about contributing to the collective good than about the personal benefits gained from a higher performance vehicle. As evidence for this relationship, one study found that participants who were primed to think about status were more likely to choose a green product over a more luxurious but non-green product of equal price (Griskevicius et al., 2010).

Whether a behavior is considered to be prosocial can depend on perceptions of (i) the strength of the collective benefits provided (how environmentally impactful the behavior is) and (ii) the costs incurred or the degree of personal sacrifice (Willer, 2009). Some curtailment behaviors may reduce environmental impacts more than efficiency behaviors (e.g. commuting by bus vs. driving a Prius), while also entailing significant non-monetary costs like time, effort, or inconvenience 
(Jansson et al., 2010). However, such behavior may be perceived as lower status because the degree of personal sacrifice is ambiguous. Without additional information, an observer will not know whether one is choosing to reduce their consumption through curtailment or is instead constrained by a lack of resources. As such, exploring when and why some behaviors are thought to be motivated by concern for the environment (and thus purposeful, costly, and prosocial) is important for understanding the status associated with various behaviors.

\subsection{Status and sustainability}

Questions about differences in status perceptions of efficiency and curtailment behaviors are not just academic. Rather, these questions have important implications for long-term efforts to shift to a more sustainable society. Many scholars argue that technological advances and efficiency gains may be insufficient for reaching long-term sustainability goals (Jackson, 2009; Meadows et al., 2004) (although other authors suggest that significant gains can be made through efficiency approaches (e.g. Attari et al., 2010;Dietz et al., 2009)). Concerns about rebound and substitution effects (Jenkins et al., 2011) and increased consumption by the growing global middle class (Myers and Kent, 2004) have lead some scholars to call for large-scale behavioral change and changes in the broader social and cultural structures that contribute to overconsumption (Meadows et al., 2004; Speth, 2012). One component of these social and cultural structures is the status signal associated with different forms of consumption. If low-cost curtailment behaviors are needed for long-term sustainability but send ambiguous signals that make them less likely to be widely adopted, then it is important to understand why particular social signals are associated with different types of pro-environmental behavior. 
While numerous studies have explored the relationship between status and consumption (see above), they have generally focused on a small number of behaviors that fall within particular domains (e.g. transportation, fashion). However, consumption decisions and pro-environmental behaviors can differ in how costly they are, the types of costs incurred (Welte and Anastasio, 2010), and the environmental benefits they produce (Dietz et al., 2009), among other characteristics (Karlin et al., 2014). The overarching objective of this study is to examine how individuals perceive the status signals sent by a variety of efficiency and curtailment behaviors. More specifically, we address the following research questions:

Q1: How do research participants conceptualize "status" and what are the characteristics of individuals and individual behaviors that they associate with high status?

Q2: Which specific pro-environmental behaviors are perceived to be relatively higher and lower in status and why are these behaviors perceived this way?

Q3: Is the status of a pro-environmental behavior related to whether the behavior is perceived to be motivated by environmental concern and, if so, why?

\section{METHODS}

We use a mixed methods approach and data that was collected as part of a larger study designed to explore perceived similarities and differences among pro-environmental behaviors. Researchers conducted interactive interviews that included hands-on activities. These methods are described in more detail below in the order they were presented to participants. Interviews were conducted 
with individuals in sessions that lasted between 45 and 90 minutes and participants were paid $\$ 15$ at the conclusion of the session. Four researchers conducted interviews with a total of 71 participants between the summer 2013 and fall 2015. All researchers were trained in the research protocol in spring 2013.

\subsection{Participants}

We used a convenience sample of seventy-one participants from in and around urban centers in central and northeastern Ohio, USA. Participants were recruited through two main channels. First, we recruited participants from a local voluntary simplicity group, a local environmental NGO, and through emails and personal connections to employees of local chapters of two national environmental/conservation NGOs. Thirty participants were identified through this process. In addition, we identified 41 participants by contacting employees in large businesses that do not have clear environmental missions (e.g. banks and financial service providers, utility companies, and manufacturing companies). Employees were contacted through personal connections that had been asked to solicit willing participants from their companies. In addition, the study was advertised with signs placed in cafes and restaurants located near high concentrations of such businesses. Eleven total participants were identified through snowball sampling.

We recruited participants through these two channels to capture diversity in respondents' levels of environmental concern and experiences with respect to pro-environmental behavior, which we then measured during the study. However, our results revealed few differences between the subsamples so we present only the combined results. 


\subsection{Behaviors}

Nineteen pro-environmental behaviors were used in the study, although not all behaviors were used for each component of the interview (see Table 2). These behaviors were chosen from a longer list identified through a literature review and were selected to capture variation in monetary cost, frequency of behavior (e.g. one-off vs. repeated), and visibility. The research team categorized these behaviors as high-cost efficiency, low-cost curtailment, or neutral (with respect to the efficiency/curtailment distinction) based on our working definitions for these terms (Table 1). However, there is disagreement about the distinction between 'efficiency' and 'curtailment' (see Karlin et al. (2014) for a review). Thus, some behaviors (e.g. plastic insulation on windows) could be classified differently based on a different interpretation of these categories.

\subsection{Perceived motivation}

To examine the perceived motivation of pro-environmental behaviors (research question 3), we used data from a task that was added to a standard repertory grid procedure (e.g. Sühlsen and Hisschemöller, 2014) that was part of the broader study. For the task, participants were given 10 cards, each containing a short description of a pro-environmental behavior (see Table 2). Participants were asked to place each card on a board divided into columns arranged on a scale from 1 to 5 (see Figure 1, perceived motivation activity). A score of 1 indicated that the behavior was not motivated by environmental concern and a score of 5 indicated that the behavior was strongly motivated by environmental concern. Participants could place as many or as few behaviors in a column as they wished. The number of behaviors was reduced to 10 from 19 for this activity in the interest of time and to make sorting the behaviors for the repertory grid activity 
more manageable. The subset of 10 behaviors (labeled in Table 2) was chosen to ensure even spread across high to low-cost behaviors and high to low-frequency behaviors.

\subsection{Q-sort: conceptualizations of status, perceived status, and indicators of status}

After completing a series of survey questions about pro-environmental behaviors (not used in this analysis), participants were guided through a sorting procedure based on Q methodology. Data from this activity allowed us to address research questions 1 and 2. In Q methodology, the subjective meanings of a particular construct are elicited by having participants sort behaviors relative to one another along a bipolar scale defined by the researcher (Goldman, 1999; McKeown and Thomas, 1988). The result of this sorting activity is a Q-sort, which serves as a model of a participant's viewpoints and can be used to uncover latent dimensions of complex constructs; in this case, social status.

Participants were presented with 19 cards, each labeled with a behavior (Table 2) and were asked to place each card in one of the 19 boxes on the Q-sort board based on the degree to which they felt that the behavior was associated with high status, low status, or was neutral in terms of status (see Figure 1, Q-sort). Prior to viewing the cards, participants were asked, "What comes to mind when you think about whether a behavior might be associated with high status or not" (research question 1). This question was repeated after participants reviewed the cards.

Participants then placed the cards on the board and made any adjustments to their initial card placement that they felt were necessary. When participants were satisfied with their choices, they were asked three additional questions: (i) why did you place the behaviors you did in the "high 
status" cells? (those with values of 2 or 3), (ii) why did you place the behaviors you did in the "low status" cells? (those with values of -2 or -3 ), (iii) which behaviors were hardest to place and why? Altogether, this exercise produced quantitative data (rankings of all behaviors) and qualitative data from participants' explanations for their rankings that allowed us to explore the factors that participants felt were indicative of status (research question 2). Qualitative data from this portion of the study also provided insights into participants' perceptions of the motivation for different behaviors (research question 3).

\subsection{Exit survey}

The last phase of the interview included a short exit survey through which we collected demographic and socio-economic information, environmental attitudes, and self-reported experience with a subset of behaviors (See SI text).

\section{ANALYSIS AND RESULTS}

Quantitative analyses were conducted in SPSS version 23 and R statistical computing version 3.2.1. The demographic characteristics for the sample are provided in Table 3. Our sample was, on average, middle-aged, highly educated, and wealthy and consisted of more males than females (56\% male, $44 \%$ female).

For all open-ended questions, the first author initially coded responses using MaxQDA version 12 qualitative data analysis software. A coding scheme was developed based on participant responses in a parallel study conducted in the UK and modified based on novel responses from the current sample. Hand-written records of participants' responses to each question were converted to digital 
text documents. Each response was broken down into distinct phrases where possible. These phrases were then individually coded such that a participant's response could include multiple phrases, each of which fit different coding categories. Phrases that did not fit the initial categories were grouped into the smallest number of new categories that could be created without losing potentially important differentiation in participants' intents (see Table S1).

Subsequently, two additional researchers, including one who was unfamiliar with the study, coded the responses. An intercoder agreement test conducted in SPSS returned a Krippendorff's alpha value of 0.506 indicating a moderate level of agreement (Landis and Koch, 1977). The coders subsequently identified differences in coding decisions and discussed those differences. This discussion and new understanding of the coding categories was used by the primary coder to recode the data, which resulted in the combination of similar coding categories and changes to the initial coding for a small number of phrases.

3.1 Results - Question 1: How do research participants conceptualize "status" and what are the characteristics of individuals and individual behaviors that they associate with high status?

Based on responses to the first two open-ended questions posed at the beginning of the Q-sort activity we explored how participants define status. Most participants found it easier to describe the characteristics of individuals that they associate with high status, rather than thinking about status in the context of behaviors. The coding categories presented in Table 4 are the factors that at least $5 \%$ of participants considered to be indicative of high status. 
Seventy-five percent of participants equated status with "money, wealth, income, or economic class". The next most common set of indicators of status was categorized as "knowledge, education, or type of job" ( $56 \%$ of the total sample), as illustrated by the following comments:

- "Hold[ing] a professional position of high rank."

- "Higher levels of education."

Participants also commented on attitudes, personality traits, or other personal characteristics that they associate with status ( $45 \%$ of the sample). These traits had both positive and negative connotations and included "high self esteem", "competitive", "focused", "credibile", "integrity", "walks the walk", "pretension”, "wastefulness", "materialistic". Status was also equated with visible possessions or markers ( $39 \%$ of the sample), which would include where one lives, what one drives, how one dresses, and where one went to school; characteristics that are often a function of wealth. In short, expensive products, services, or opportunities, and the observability of each, were considered indicative of status.

Thirty-one percent of participants also noted that influence and leadership are associated with status. For example, participants suggested that status was indicated by:

"...high positions that relate to responsibility and high influence in the community..." “...a leadership role or natural demeanor for leadership."

Interestingly, $11 \%$ of participants equated prosociality with status and $10 \%$ of participants did so for pro-environmentalism. For instance, one participant suggested that high status individuals are:

"People who contribute to society by serving others and exhibit prosocial behavior that don't require much money. People who devote other aspects of life, apart from money, to serving others". (Male, 61 years old, 11/30/2013)

Another respondent noted that: 
"status is being active and doing things to help the environment" (Female, 61 years old, 02/06/2014)

\subsection{Results - Question 2: Which specific pro-environmental behaviors are perceived to be} relatively higher and lower in status and why are these behaviors perceived this way?

Mean status scores were calculated from the Q-sort activity (see Table 5). Solar, renewable energy, local food, and fuel-efficient car were ranked highest in relative status (mean status score of $\geq 1$ ). Similarly, repair clothes, insulate windows, and bus were ranked lowest in status and were the only behaviors with a mean status ranking of $<-1$. Overall, participants rated efficiency behaviors higher status than curtailment behaviors. The four highest status behaviors were efficiency and three of the lowest status behaviors were curtailment. In addition, only two curtailment behaviors had positive mean status scores (vegetarian diet and compost). Conversely, tire pressure and insulate windows were the only efficiency behaviors with negative mean scores.

Qualitative data from the Q-sort provided insight into the rationales behind participants' ratings of status (see Table 4). "Money" was the most common explanation for why behaviors were placed in the high status columns (77\% of participants). The next most commonly elicited explanations were that behaviors are adopted to make a statement ("show-off" behaviors) (17\% of participants) and require having sufficient time or flexible time ("time availability") (17\% of participants). With regards to time, for instance, one respondent noted that high status behaviors:

“...take personal commitment of some sort - financial commitment or a personal investment of time." (Female, 56 years old, 02/12/2014)

And another respondent rated a behavior as high status because it: 
"indicates having more time" (Female, 39 years old, 10/08/2015)

In addition to the amount of time required to engage in certain behaviors, other non-monetary costs were used to characterize high status behaviors. For instance, several participants noted that some behaviors require knowledge, awareness or education, which is then used to infer status. When asked why certain behaviors were rated as being high status, one respondent suggested that there is,

- (local food) "...the perception that locally grown is better, pesticide-free is better...requires education to feel like it makes a difference, and money to do it." (Female, 76 years old, 06/14/2013)

other responses to this question included:

(compost) "...more about having an increased awareness than about money" (Male, 55 years old, 12/16/2013)

(renewable energy) "Requires a level of sophistication/education as a consumer to be aware of this as an option, which are common traits of people of high status." (Female, 50 years old, 12/09/2013)

- (compost) "Involves purchasing decisions and understanding of composting, which indicates an availability of time." (Male, 43 years old, 11/24/2013)

Finally, four respondents stated that behaviors are considered high status if they indicate that one is acting prosocially. For instance,

- "All these behaviors...involve making a statement that you are making an important commitment to the community, the world, and to others in general, rather than just focusing on personal benefits. (Male, 53 years old, 12/17/2013)

The most common explanation for why behaviors were rated low status was, "lack of financial means" ( $83 \%$ of participants) (see Table 4). This explanation mirrors the emphasis on wealth for 
high status behaviors. Other indicators of low status included "social stigma" (23\% of participants), little freedom of choice" (behavior adopted out of necessity) (15\% of participants), and "lack of visibility" ( $10 \%$ of participants).

3.3 Results - Question 3: Is the status of a pro-environmental behavior related to whether the behavior is perceived to be motivated by environmental concern and, if so, why?

We first calculated the mean score for the degree to which each of the ten behaviors was perceived to be motivated by environmental concern (see Table 6). Renewable energy $($ mean $=$ 4.21) and solar $($ mean $=4.17)$ were considered to be most motivated by environmental concern while repair clothes $($ mean $=2.41)$ and tire pressure $($ mean $=2.51)$ were rated as least motivated by environmental concern.

We then fit a bivariate linear regression to examine the relationship between average motivation scores (independent variable) and the average status scores (dependent variable). The model output suggests that there is a positive and significant relationship such that behaviors that participants perceive to be more motivated by environmental concern are also perceived to be higher status $(\beta=1.75, \mathrm{t}=3.76, \mathrm{p}=0.01)$.

Responses to the open-ended questions provided further insights into the relationship between motivation and status. Fifty-five percent of participants mentioned behavioral motivation or an indication that the behavior is a choice as a factor in signaling status. For instance, when asked 
why behaviors were rated as high status, some participants noted that adopting such behaviors was indicative of choice:

- “...involves donating something and so it is not done out of necessity." (Male, 61 years old, 11/30/2013)

- “...a behavioral choice that requires an increased awareness of an issue.” (Male, 45 years old, 12/17/2013)

Additionally, some participants had difficulty placing behaviors because of the lack of clarity about the motivation:

- “...it depends on motivation. If motivated by philosophy or lifestyle, then it is high status, if motivated by saving money, then it is low status." (Male, 59 years old, 08/12/2015)

- "...for these behaviors in particular, it is the motivation behind the behavior that matters. The reasoning behind what people do is a factor in people's status. If you are doing something to save money, it's not high status, but doing the same thing out of concern for the environment would make it higher status." (Male, 22 years old, 06/24/2013)

Most commonly, however, participants said that they associated behaviors with low status because they were perceived as a need rather than a choice.

- “...it's about needs versus wants - people need to do these things." (Female, 55 years old, 01/31/2014)

- “...associated with people who don't have a choice” (Male, 50 years old, 08/14/2015)

- "...people do this out of necessity or to save money - not for environmental reasons" (Female, 48 years old, 07/08/2013)

Thus, quantitative and qualitative data suggest that one's understanding of the motivation for a behavior can shape the perceived status of that behavior. Behaviors that are adopted for prosocial 
or pro-environmental motivations signal that the behavior is a choice and thus that there is a willingness to absorb personal costs.

\section{DISCUSSION}

This study explored differences in the perceptions of status associated with efficiency and curtailment behaviors. The following patterns emerged from the study:

Research Question 1: status is generally considered to be associated with wealth (although type of employment, attitudes and personal characteristics, visible possessions, and leadership/influence were also noted as indicators of status)

Research Question 2: high-cost efficiency behaviors are perceived to be higher status and motivated more by environmental concern than curtailment behaviors and the perceived status of a behavior was most frequently related to the costs of the behavior (primarily monetary but also non-monetary)

Research Question 3: perceived motivation for the behavior was significantly associated with perceived status because understanding that one is motivated by environmental concern clarifies the signal that personal costs are involved

In addition, we found that contextual cues about the person that adopted the behavior or the social/physical environment in which they are embedded can affect perceptions of the motivation for a behavior and subsequently perceived status. The key result of the study is that it is often unclear whether adopting low-cost curtailment behaviors is a choice rather than being driven by 
financial need. Ambiguity about the intentionality of curtailment behaviors results in such behaviors being perceived as lower status.

\subsection{Wealth, time, visibility and status}

Efficiency behaviors were rated higher in status relative to curtailment behaviors and this was largely based on monetary considerations. These results support previous research suggesting that low-cost curtailment behaviors are either stigmatized (Sadalla and Krull, 1995) or are, at best, neutral on a low-to-high status scale (Brooks and Wilson, 2015; Welte and Anastasio, 2010). The results also support previous work suggesting that monetary cost is an important part of the status value of a 'green' product or action (Griskevicius et al., 2010).

The role of wealth in perceptions of status may also be manifest through the amount of time required for individuals to adopt a behavior or the flexibility of time required to do so. For instance, one respondent described their perspective on high status by noting:

- "Free time is a luxury - more money tends to equal more time. People can arrange their lives in a way they choose. Higher status things require a certain amount of free time." (Female, 61 years old, 06/11/2013)

In addition to wealth, behavioral visibility may also be important for status signals (Griskevicius et al., 2010). Twenty-eight participants noted that the status of a behavior is partly related to how visible it is. In other studies, some behaviors that are highly visible, such as purchasing a fuelefficient car and installing solar panels, and have been found to have high symbolic value and status effects (Dastrup et al., 2012; Delgado et al., 2015; Sexton and Sexton, 2011; Sütterlin and Siegrist, 2014). However, not all behaviors rated as high status in this study - such as renewable 
energy or local food - are necessarily visible, although it is possible that participants had particularly visible manifestations in mind.

The relationship between visibility and status is not always straightforward (Griskevicius et al. 2011) and may depend on to whom the behavior is visible (Ariely et al., 2009). It is possible that some inconspicuous behaviors may be visible and status enhancing only within one's social group, while others are associated with high status because of their visibility to the general public (Berger and Ward, 2010). Examination of variations in visibility of behaviors and status within and across social groups remains an important area for future work.

\subsection{Curtailment, non-monetary costs, and status}

Importantly, this study provides insights into why curtailment behaviors tend to be associated with lower status even though they can entail high personal costs and provide collective benefits. The quantitative and qualitative data both indicate that there is a relationship between the motivation for a behavior and its status ranking. This result matches previous work suggesting that perceived intentionality is important for status perceptions (Belleza et al., 2014; Bliege Bird and Smith, 2005). In this study, participants perceived efficiency behaviors to signal financial means and perceived efficiency to be more motivated by environmental concern than curtailment behaviors. Our results suggest that participants were less certain that curtailment behaviors were intentional because they are lower cost and because the motivation for adopting such behaviors is less clear. Uncertainty about whether a behavior is a choice or a necessity also makes it unclear whether an individual is purposefully absorbing personal costs to provide collective benefits, which is the hallmark of prosocial behavior. The absence of a clear signal that a pro- 
environmental behavior is prosocial can explain why curtailment behaviors were associated with lower status.

While the expense of a product of behavior was frequently noted as an indicator of status, some participants also explained their status rankings by pointing to non-monetary costs including those associated with the effort devoted to the behavior and time and effort spent acquiring the requisite level of education, knowledge, understanding or awareness. Such considerations resonate with the concept of cultural capital which includes skills, credentials, patterns of speech, or capacities that are associated with higher status (Bourdieu, 1986), suggesting that the investment of time or other non-monetary resources in behaviors also potentially signals status. This concept is important because, while our results suggest that the monetary value of the behavior more strongly signals that the adoption of pro-environmental behaviors is voluntary, non-monetary costs can, for some participants, can also contribute to that signal.

\subsection{Contextual cues}

Responses to the open ended questions indicated that perceptions of status signals may be context dependent. Previous studies have demonstrated that context is an important factor when it comes to our perceptions of others. For instance, our interpretation of other people's emotions depends not just on their facial expressions, but on our knowledge of the context in which the individual is embedded (Barrett et al., 2011). In addition, perceptions of pro-environmental actions can change significantly when an observer is presented with information that provides clues about the wealth and environmental attitudes of the person engaged in these actions (Brooks and Wilson, 2015). 
The importance of context for status signaling emerged several times in the present study. For instance, in reference to bus and bike, one participant said:

- "People of any status could engage in these behaviors and they could be motivated by money savings, or for making a statement.” (Male, 52 years old, 11/22/2013)

Similarly, when one participant was asked what kind of information they use to determine whether a behavior is motivated by environmental concern, the response was:

- "It's people I know well and they tell me. But I can also tell from their other behaviors." (Male, 22 years old, 06/24/2013)

The first quote illustrates that ambiguity about who is engaged in the behavior can impact one's status ranking. The second quote illustrates that one can rely on information from other behaviors adopted by the individual to clarify their judgment about whether a behavior is motivated by environmental concern and thus worthy of higher status.

Other contextual conditions can also affect perceptions of status. For instance, the cost of a behavior may be shaped by local infrastructure and features of the built environment. A clean, efficient, and punctual public transit system can make riding the bus more comfortable and convenient, which may reduce the perception that only those who cannot afford other options would take the bus. One participant alluded to this by noting that bus and local food were difficult to rate because there are "nuances that depend on location". This participant also noted that, - "... [taking the bus] in urban settings, it may just be more convenient." and that, - “...in rural settings [buying local food] is just what you do, so it's not associated with status. In urban settings, it costs you more..."

(Male, 43 years old, 10/10/2013) 
Similarly, when noting that compost was hard to place, one respondent said that it is: - “...not a well-known view. People get it but it's also kind of gross. If more people did it, I would have placed it differently." (Male, 45 years old, 07/01/2013)

Another participant who had difficulty placing vegetarian diet commented that it: - “...cannot only be attributed to status, but health, religion, environmental concern, etc. The reason to engage in this behavior is highly situational." (Female, 45 years old, 11/01/2013)

Thus, information about who has adopted the behavior and where they live can shape our understanding of the motivation for behaviors, and subsequently perceptions of status. Future work could compare social signals associated with behaviors in municipalities that have different infrastructure, amenities, or policies that may affect the costs, benefits, and commonness of behaviors.

In addition, the perceived status of a behavior may also depend on social context. For instance, a behavior or product that is common in a particular social group may lose its distinctiveness and thus no longer be perceived as high status. This same behavior may retain its status association in another social group where the behavior is less common, but has been adopted by respected members of that group. Social context and perceptions of commonness were particularly relevant for vegetarian diet, which was one of two curtailment behaviors that had a higher status ranking than some efficiency behaviors. Several participants indicated they consider a vegetarian diet to be highly visible, more expensive, and indicative of wealth or education. For instance, when describing why they rated vegetarian diet as high status, participants noted that: 
- "The person who preoccupies themselves with a particular diet must have more time, and financial and intellectual means to follow with it." (Female, 45 years old, 11/01/2013)

- “...it is an expensive behavior to engage in.” (Male, 43 years old, 11/21/2013)

- “...it requires a high amount of education, money, and luxury of time.” (Male, 55 years

old, 12/16/2013)

Conversely, other participants noted that vegetarian diet was one of the hardest behaviors to rate.

This ambivalence about vegetarianism may stem from uncertainty about the costs associated with

it as well as the sense that it is much more common than in the past:

- "[eating vegetarian] can be costly, but if you know how to cook it, it can be cheap."

(Female, 61 years old, 06/11/213)

- “...it's not really a sign of status - maybe it was 10 years ago. Now there are more cooking shows and there's more information available about food." (Female, 61 years old, 07/03/2013)

- “... eating vegetarian could be viewed as saving the environment or saving money...

eating vegetarian used to be more high status, but now it's more common, trendy."

(Female, 39 years old, 07/03/2013)

- “... [eating vegetarian] is socially hip, but supported by saving money." (Male, 28 years

old, 07/03/2013)

These different perspectives on the commonness of a vegetarian diet may indicate differences in norms in different social groups. When the commonness of behaviors differs between social groups so can perceptions of the costs of the behaviors and perceptions of the knowledge and skill required to adopt them.

\subsection{Implications}


The most obvious conclusion from this study is that because efficiency faces fewer social obstacles in the form of status, it may be the most effective way of reducing environmental impacts (Attari et al., 2010). However, concerns about the long-term efficacy of this approach for meeting sustainability goals remain. While efficiency can reduce environmental impacts and may be more socially acceptable, it perpetuates a society that values the acquisition of material goods. In contrast, curtailing material and energy consumption may be critical for long-term sustainability but is hindered by social, psychological, and cultural factors including the perception that such a lifestyle signifies low status. This study reinforces the idea that there can be important social obstacles to increasing the adoption of curtailment behaviors

This study was motivated by a desire to understand social obstacles, so addressing the commonness of a behavior is important. For instance, some participants suggested that vegetarianism lost its value as an indicator of status because it was perceived as being more common. This might lead one to conclude that making pro-environmental behaviors more accessible and common might undercut their ability to signal status. Griskevicius et al. (2011:400) reach such a conclusion when they suggest that making "green products cheaper, easier to buy, or more time-saving can actually undercut their utility as a signal of environmentalist/altruist dedication", and conclude that "electric cars might be seen as more prestigious and more desirable if recharging stations are harder to find and take longer to recharge the batteries..."

However, if the goal is to increase the adoption of a behavior, it may be counter-productive to try to maintain the status signal by restricting access. Status signals are not relevant for all behaviors, for a given behavior at all points in time, or for a given behavior in all contexts. Instead, social 
signals evolve (Skyrms, 2010). While providing a signal of high status may initially be important for some pro-environmental behaviors, as the behavior becomes more common it may be important to allow the status signal to evolve rather than trying to restrict access to the behavior. Ideally, the status-signal will shift to even more environmentally-friendly products or behaviors. For instance, if the Prius loses its value as a marker of status as a result of an increase in market share, perhaps the status signal will shift to the all-electric Tesla (Young, 2015), at least among particular social groups. Similarly, as vegetarianism loses its function as a marker of status by becoming more common, the marker of status may shift to veganism (Khomani, 2015). Thus, it may be better to identify and promote another, more environmentally-friendly behavior that will then serve as the new signal of one's prosociality. This process would represent a status race to the top (more environmentally-friendly consumption) rather than a status race to the bottom (conspicuous over-consumption).

\subsection{Sampling limitations and future directions}

We initially aimed to have two subgroups in our sample because there is evidence that the interpretation of social signals can depend on the audience (Ariely et al., 2009; Cronk, 2005; Willer, 2009). Some social signals are understood only by individuals within a particular social group and/or with a specialized knowledge base (Berger and Ward, 2010; Smaldino et al., 2015). For example, the pro-environmental signal associated with a Toyota Prius was found to be clearer and to have greater value in some social groups than in others (Sexton and Sexton, 2011).

Recall that subgroups were initially defined by whether participants were recruited through (i) environmental organizations and the voluntary simplicity group or (ii) local businesses. We tested 
whether these broad groupings affected perceptions of status by comparing the two broadly defined subgroups in our sample. With data from our exit survey, we also generated empirically derived subgroups using discriminant analysis to distinguish individuals that scored high on environmental values and self-reported experience with pro-environmental behaviors from those that scored low in those respects. Neither approach to defining subgroups (by sampling approach or empirically) showed significant group-wise differences. This result may be attributable to selection bias. If participants from local businesses volunteered for the study (or were referred by other participants) because they were aware of, and interested in environmental issues, this would have reduced variation between groups and limited our ability to uncover group-level variation in perceptions of status.

However, future research could examine potential group-level differences by recruiting participants from more well-defined groups that are less likely to overlap in terms of their levels of environmental awareness or concern or in their adoption of pro-environmental behaviors. Alternately, future research could examine whether and how individual characteristics (e.g. variation in political ideology) affects perceptions of pro-environmental behavior regardless of group affiliation.

In addition, our sample was, on average, relatively wealthy and highly educated. A sample of respondents with more diverse socio-economic backgrounds could produce different results. For instance, if some behaviors (e.g. riding the bus, turning down the heat) are more common among individuals with lower incomes, these behaviors could be perceived as being status-neutral as opposed to lower status. Conversely, if respondents with lower income and/or less education are 
even more attentive to indicators of wealth, this could result in an even stronger relationship between the monetary cost of pro-environmental behaviors and status. Similarly, income has been found to be positively associated with environmental concern (Franzen and Vogl 2013). If individuals with lower income are less concerned about environmental issues, they may not consider behaviors motivated by environmental concern to be as high in status. Potential changes in study outcomes as a result of a more socio-economically diverse sample could also be contingent on geographic location (e.g. if income and/or educational inequality in a community intensifies positional concerns (Heffetz and Frank 2008)) and group-level dynamics (the number, diversity, and types of interactions among social groups in a region). These remain important areas for future study.

\section{CONCLUSION}

This study suggests that for relatively wealthy, well-educated participants who live in and around urban centers in Ohio, efficiency behaviors are perceived to be higher status than curtailment behaviors because of the combined signal of wealth and environmental motivation. The overall results suggest that there may be significant social barriers to the spread of low-cost curtailment behaviors. In the long term, those who argue that overall reductions in consumption will be necessary to achieve long-term sustainability goals must address this barrier. Our results suggest that one could avoid perceptions of low status by clarifying the motivation for adopting curtailment behaviors or low consumption lifestyles in a way that more strongly signals that the behavior is a conscious choice. More immediately, it may be easier to focus on economic or other mechanisms to increase efficiency, which is generally not hindered by perceptions of low status. Additional research is needed to explore whether the patterns identified here hold across a wider 
variety of social, cultural, economic and physical contexts. Ultimately, altering the somewhat negative perception of curtailment behaviors may require both individual and broader sociocultural change. Individual efforts to demonstrate that curtailment behaviors are motivated by environmental concern (where appropriate) can help clarify the signal and broader socio-cultural and economic change can help increase awareness and appreciation of the non-monetary costs and value of adopting such behaviors.

\section{Acknowledgements}

We thank two anonymous reviewers for their helpful comments as well as Ellen Eilers, Hugh Walpole, James Ryan, and Ian Adams for assistance with data collection and coding. This study was funded by the Ohio Agricultural Research and Development Center and a small grant from the Decision Sciences Collaborative at The Ohio State University.

\section{Literature cited.}

Ariely, D., Bracha, A., Meier, S., 2009. Doing good or doing well? image motivation and monetary incentvives in behaving prosocially. American Economic Review 99, 544-555.

Attari, S.Z., DeKay, M.L., Davidson, C.I., de Bruine, W.B., 2010. Public perceptions of energy consumption and savings. Proceedings of the National Academy of Sciences 107, 16054-16059.

Barrett, L.F., Mequita, B., Gendron, M., 2011. Context in emotion perception. Current Directions in Psychological Science 20, 286-290.

Belleza, S., Gino, F., Keinan, A., 2014. The red sneakers effect: inferring status and competence from signals of nonconformity. Journal of Consumer Research 41, 35-54.

Berger, J., Heath, C., 2008. Who drives divergence? Identity signaling, outgroup dissimilarity, and the abandonment of cultural tastes. Journal of Personality and Social Psychology 95, 593-607.

Berger, J., Ward, M., 2010. Subtle Signals of Inconspicuous Consumption. Journal of Consumer Research 37, 555-569.

Bliege Bird, R., Smith, E.A., 2005. Signaling theory, strategic interaction, and symbolic capital. Curr Anthropol 46, 221-248.

Bourdieu, P., 1986. The forms of capital, in: Richardson, J. (Ed.), Handbook of Theory and Research for the Sociology of Education. Greenwood Pres, Westport, CT.

Brooks, J.S., Wilson, C., 2015. The influence of contextual cues on the perceived status of consumptionreducing behavior. Ecol Econ 117, 108-117. 
Cohen, G.L., Prinstein, M.J., 2006. Peer contagion of aggression and healh-risk behavior among adolescent males: an experimental investigation of effects on public conduct and private attitudes. Child Development 77, 967-983.

Cronk, L., 2005. The application of animal signaling theory to human phenomena: some thoughts and clarifications. Social Science Information 44, 603-620.

Dastrup, S.R., Zivin, J.G., Costa, D.L., Kahn, M.E., 2012. Understanding the solar home price premium: electricity generation and green social status. . European Economic Review 56.

Delgado, M.S., Harriger, J.L., Khanna, N., 2015. The value of environmental status signaling. Ecol Econ 111, 1-11.

Dietz, T., Gardner, G.T., Gilligan, J., Stern, P.C., Vandenbergh, M.P., 2009. Household actions can provide a behavioral wedge to rapidly reduce US carbon emissions. Proc Natl Acad Sci U S A 106, $18452-$ 18456.

Franzen, A. and D. Vogl. 2013. Two decades of measuring environmental attitudes: a comparative analysis of 33 countries. Global Environmental Change. 23: 5, 1001-1008.

Gintis, H., Smith, E.A., Bowles, S., 2001. Costly signaling and cooperation. Journal of Theoretical Biology 213, 103-119.

Goldman, I. 1999. Q-Methodology as Process and Context in Interpretivism, Communication, and Psychoanalytic Psychotherapy Research. The Psychological Record 49, 589-604.

Griskevicius, V., Tybur, J.M., Van den Bergh, B., 2010. Going green to be seen: status, reputation, and conspicuous conservation. J Pers Soc Psychol 98, 392-404.

Hardy, C.L., van Vugt, M., 2006. Nice guys finish first: the competitive altruism hypothesis. Personality and Social Psychology Bulletin 32, 1402-1413.

Heffetz, O. and Frank, R.H. 2008. Preferences for status: evidence and economic implications. Johnson School Research Paper Series \#05-09. 1-38.

Henrich, J., 2009. The evolution of costly displays, cooperation and religion: credibility enhancing displays and their implications for cultural evolution. Evolution and Human Behavior 30.

Henrich, J., Gil-White, F.J., 2001. The evolution of prestige: freely conferred deference as a mechanism for enhancing benefits of cultural transmission. Evolution and Human Behavior 22, 165-196.

Hirsch, F., 1976. Social Limits to Growth. Harvard University Press, Cambridge, MA.

Hunter, L.M., Hatch, A., Johnson, A., 2004. Cross-national gender variation in environmental behaviors. Social Science Quarterly 85, 677-694.

Jackson, T., 2009. Prosperity Without Growth: Economics For a Finite Planet. Earthscan, New York, NY.

Jansson, J., Marell, A., Nordlund, A., 2010. Green consumer behavior: determinants of curtailment and eco-innovation adoption. Journal of Consumer Marketing 27, 358-370.

Jenkins, J., Norhaus, T., Shellenberger, M., 2011. Energy emergence: rebound \& backfire as emergent phenomena.

Johansson-Stenman, O., Martinsson, P., 2006. Honestly, why are you driving a BMW? J Econ Behav Organ 60, 129-146.

Karlin, B., Davis, N., Sanguinetti, A., Gamble, K., Kirkby, D., Stokols, D., 2014. Dimensions of conservation: exploring differences among energy behaviors. Environment and Behavior 46, 423-452.

Khomani, N., 2015. From Beyonce to the Baftas, vegan culture gets star status, The Guardian, UK. 
Landis, J.R., Koch, C.G., 1977. The measurement of observer agreement for categorical data. Biometrics 33, 159-174.

McKeown, B., Thomas, D., 1988. Quantitative Applications in the Social Sciences: Q Methodology. SAGE Publications, Inc., Thousand Oaks, CA.

Meadows, D.H., Randers, J., Meadows, D., 2004. Limits to Growth: The 30-Year Update. Chelsea Green Publishing Co., White River Junction, VT.

Myers, N., Kent, J., 2004. The New Consumers: The Influence of Affluence on the Environment. Island Press, Washington D.C.

Richerson, P.J., Boyd, R., 2005. Not by Genes Alone: How Culture Transformed Human Evolution. University of Chicago Press, Chicago.

Sadalla, E.K., Krull, J.L., 1995. Self-Presentational Barriers to Resource Conservation. Environment and Behavior 27, 328-353.

Sexton, S.E., Sexton, A.L., 2011. Conspicuous conservation: the Prius effect and willingness to pay for environmental bona fides.

Skyrms, B., 2010. Signals: Evolution, Learning, and Information. Oxford University Press, New York, NY.

Smaldino, P., Flamson, T.J., McElreath, R., 2015. Evolution of cooperation via covert signaling.

Speth, J.G., 2012. American passage: towards a new ecoonomy and a new politics. Ecol Econ 84, 181-186.

Steg, L., Vlek, C., 2009. Encouraging pro-environmental behavior: an integrative review and research agenda. Journal of Environmental Psychology 29, 309-317.

Stern, P.C., 2000. Toward a coherent theory of environmentally significant behavior. Journal of Social Issues 56, 407-424.

Sühlsen, K. and Hisschemöller, M., 2014. Lobbying the 'Energiewende'. Assessing the effectiveness of strategies to promote the renewable energy business in Germany. Energy Policy, 69, 316-325

Sütterlin, B., Siegrist, M., 2014. The reliance on symbolically significant behavioral attributes when judging energy consumption behaviors. Journal of Environmental Psychology 40, 259-272.

Van den Bulte, C., Stremersch, S., 2004. Social contagion and income heterogeneity in new product diffusion: a meta-analytic test. Marketing Science 23, 530-544.

van Vugt, M., Roberts, G., Hardy, C., 2007. Competitive altruism: development of reputation-based cooperation in groups, in: Dunbar, R., Barrett, L. (Eds.), Handbook of Evolutionary Psychology. Oxford University Press, Oxford, England, pp. 531-540.

Veblen, T., 1899. The theory of the leisure class; an economic study in the evolution of institutions. The Macmillan Company, New York.

Welte, T.H.L., Anastasio, P.A., 2010. To Conserve or Not to Conserve: Is Status the Question? Environment and Behavior 42, 845-863.

Willer, R., 2009. Groups Reward Individual Sacrifice: The Status Solution to the Collective Action Problem. American Sociological Review 74, 23-43.

Young, A., 2015. Tesla Model S: The Only Electric Car in Demand Right Now As Low US Gas Prices Batter Plug-In Car Sales, International Business Times, United States. 
Zabkar, V., Hosta, M., 2013. Willingness to act and environmentally conscious consumer behavior: can prosocial status perceptions help overcome the gap? international Journal of Consumer Studies 37, 257264.

Zelezny, L.C., Chua, P., Aldrich, C., 2000. New ways of thinking about environmentalism: elaborating on gender differences in environmentalism. Journal of Social Issues 56, 443-457.

Table 1. Definitions of key terms

Sustainable consumption/ Pro-environmental behavior
Pro-environmental behavior is action undertaken which "...harms the environment as little as possible or even benefits the environment" (Steg and Vlek, 2009: 309; Stern, 2000). We consider sustainable consumption to be a form of pro-environmental behavior in that some products are purchased (or the purchase of material goods is avoided) in order to benefit the environment. There is no consensus definition of 'sustainable consumption (Jackson and Michaelis, 2003), but we break it into two widely-accepted categories, efficiency and curtailment

Efficiency

Curtailment
Consumption that provides the same good or service as consumptionintensive behavior, but with lower environmental impact, which is typically achieved through the purchase of a product that increases efficiency. Our emphasis is on the cost of the product and the absence of behavioral change (Brooks and Wilson 2015, Jansson et al. 2010, Karlin et al. 2014).

Behaviors that provide either less of a good or service, or a qualitatively different good or service, than consumption-intensive behaviors but with lower environmental impact. The reduction or change in the good or service is typically achieved through behavioral change rather than the purchase of a particular product. These behaviors typically have no or low monetary costs but potentially substantial non-monetary costs (e.g. time, knowledge, effort, inconvenience) (Brooks and Wilson 2015, Jansson et al. 2010, Karlin et al. 2014). 
Table 2. Categorization of behaviors with a corresponding justification for the categorization based on the definitions provided in the Table 1.

\section{Curtailment}

Efficiency

Repair used clothes instead of buying new ones (repair clothes) ${ }^{\text {a }}$ : less of a good; saves money, but requires time.

Eat vegetarian food instead of meat (vegetarian diet) $^{\mathbf{a}, \mathbf{b}}$ : qualitatively different good; may save money and require additional knowledge, effort, or inconvenience

Turn down heating when at home during the day (turn down heat) ${ }^{\text {b }}$ : less of a good; saves money but may lead to discomfort

Take shorter showers (shower): less of a good; saves money but may reduce enjoyement

Use bicycle instead of car for short distance journeys (bike) ${ }^{\mathbf{a}, \mathbf{b}}$ : qualitatively different service; saves money, but requires additional effort and time, which may lead to less overall travel.

Wash clothes at low temperature (wash): qualitatively different service; can save money but may reduce quality

Use bus instead of car for short distance journeys (bus) ${ }^{\mathbf{a}, \mathbf{b}}$ : qualitatively different service; saves money, but requires additional time, and inconvenience, which may leading to less overall travel.

Compost kitchen waste (compost): qualitatively different service; food is broken down rather than being sent to dump. Requires additional time and inconvenience.

Reuse bags when shopping (bags): reduction in use of a good (plastic bags); requires effort to remember to bags

a. subset of behaviors used in the environmental motivation activity

b. participants were asked how much experience they had with these behaviors in the exit survey
Install solar panels on roof (solar) ${ }^{\text {a,b }}$ : provides energy more efficiently; high cost item.

Buy locally produced food (local food $)^{\mathbf{b}}$ : provides food with a smaller carbon footprint than non-local food produced in the same manner; may be more expensive than alternatives (particularly if purchased at a farmer's market).

Install energy efficient light bulbs (light bulbs) $^{\mathbf{a}, \mathbf{b}}$ : provides lighting more efficiently; perceived to be higher cost than standard bulbs

Buy fuel-efficient car (fuel-efficient (car $^{\mathbf{a}, \mathbf{b}}$ : provides mobility more efficiently; high cost item.

Purchase renewable energy from your energy provider (renewable energy) ${ }^{\mathbf{a}, \mathbf{b}}$ : provides energy from more environmentally-friendly sources; perceived to be more expensive that nonrenewable energy

Maintain car tires at correct pressure (tire pressure) $^{\mathbf{a}, \mathbf{b}}$ : provides same service more efficiently; low cost

Put sheets of plastic insulation on windows (insulate windows) ${ }^{\mathrm{a}}$ : provides same service (heating) but more efficiently; higher cost than no insulation, but cheaper than alternative solutions

Install attic or wall insulation (wall insulation): provides same service (heating); may entail substantial upfront costs.

Neutral

Donate clothes no longer being used to charity (donate clothes): no personal costs, no change in service.

Participate in public protests about environmental issues (protest): no change in service or use of a good; costs can include time and inconvenience. 
Table 3. Demographic Information for Sample

Gender $\quad$ Male $=56 \%(40)$

Female $=44 \%(31)$

Average Age 48.7 years

Education $\quad$ Some high school $=0 \%(0)$

High school diploma/GED $=0 \%(0)$

Some college $=6 \%(4)$

Bachelor's degree $=45 \%$ (32)

Graduate degree $=49 \%$ (35)

$\begin{array}{ll}\text { Income } & <\$ 20,000=0 \%(0) \\ & \$ 20-39,000=6 \%(4) \\ & \$ 40-59,000=13 \%(9) \\ & \$ 60-79,000=7 \%(5) \\ & \$ 80-100,000=13 \%(9) \\ & >\$ 100,000=55 \%(39)\end{array}$


Table 4. Explanations for why behaviors were placed in high status and low status columns in the Q-sort activity and high status indicators noted by participants. The percentage of the sample whose responses fit within each category is shown. Percentages add up to more than 100 because participants' responses could have fit multiple categories The number of participants is shown in parentheses. For explanations of categories, see Table S1.

\begin{tabular}{|c|c|}
\hline Category & $\begin{array}{c}\text { Percentage of } \\
\text { participants } \\
N=71 \\
\end{array}$ \\
\hline \multicolumn{2}{|l|}{ INDICATORS OF HIGH STATUS } \\
\hline 1a. Money & $75 \%(53)$ \\
\hline 5a. Knowledge, education, or type of job & $56 \%(40)$ \\
\hline 4. Attitudes or personality traits & $45 \%(32)$ \\
\hline 2aii. Visible possessions or markers & $39 \%(28)$ \\
\hline 6. Influence and leadership & $31 \%(22)$ \\
\hline 1bi. Money as a precondition to behavior & $24 \%(17)$ \\
\hline 2bii. "Show-off" behaviors & $13 \%(9)$ \\
\hline 11. Prosociality & $11 \%(8)$ \\
\hline 12. Pro-environmentalism & $10 \%(7)$ \\
\hline 2aiii. Activities & $10 \%(7)$ \\
\hline 8b. Moral decision & $8 \%(6)$ \\
\hline 2biv. Group affiliation & $7 \%(5)$ \\
\hline \multicolumn{2}{|c|}{ REASON BEHAVIOR WAS PLACED AS HIGH STATUS } \\
\hline 1bi. Behavior requires wealth/money & $77 \%(55)$ \\
\hline 2bii. "Show-off behaviors" & $17 \%(12)$ \\
\hline 7bii. Behavior requires time & $17 \%(12)$ \\
\hline $\begin{array}{l}\text { 5b. Behavior requires knowledge, awareness, education, or } \\
\text { employment }\end{array}$ & $17 \%(12)$ \\
\hline $\begin{array}{l}\text { 4. Behaviors is associated with certain attitudes or personality } \\
\text { traits }\end{array}$ & $10 \%(7)$ \\
\hline 7ai. Behavior indicates freedom of choice & $7 \%(5)$ \\
\hline $2 \mathrm{bv}$. Behavior indicates that one is a trendsetter & $7 \%(5)$ \\
\hline 11. Behavior indicates prosociality & $6 \%(4)$ \\
\hline 2biii. Behavior is a statement of identity & $6 \%(4)$ \\
\hline \multicolumn{2}{|c|}{ REASON BEHAVIOR WAS PLACED AS LOW STATUS } \\
\hline 1bii. Done out of necessity/lack of financial means & $83 \%(59)$ \\
\hline 2c. Behavior carries a social stigma & $23 \%(16)$ \\
\hline $\begin{array}{l}\text { 7aii. Adoption of the behavior indicates little or no freedom of } \\
\text { choice }\end{array}$ & $15 \%(11)$ \\
\hline 2bvi. Behavior is not publically visible & $10 \%(7)$ \\
\hline
\end{tabular}


Table 5. Mean status scores and standard deviations for each behavior. Bold cells are efficiency behaviors, italic cells are curtailment, and bold and italic cells are neutral.

\begin{tabular}{|c|c|}
\hline Behavior & Mean (st. dev.) \\
\hline solar & $2.42(0.82)$ \\
\hline renewable energy & $1.58(2.21)$ \\
\hline local food & $1.27(1.03)$ \\
\hline fuel-efficient car & $1.25(1.07)$ \\
\hline protest & $0.51(1.16)$ \\
\hline vegetarian diet & $0.51(0.86)$ \\
\hline donate clothes & 0.37 (1.11) \\
\hline light bulbs & $0.31(0.92)$ \\
\hline compost & $0.20(1.04)$ \\
\hline wall insulation & $0.18(1.09)$ \\
\hline bags & $-0.07(1.00)$ \\
\hline tire pressure & $-0.34(0.91)$ \\
\hline bike & $-0.39(1.09)$ \\
\hline turn down heat & $-0.70(1.10)$ \\
\hline wash & $-0.76(0.90)$ \\
\hline shower & $-1.00(0.91)$ \\
\hline bus & $-1.38(1.01)$ \\
\hline insulate windows & $-1.59(1.13)$ \\
\hline repair clothes & $-2.10(1.00)$ \\
\hline
\end{tabular}

Table 6. Mean scores for the degree to which a behavior is perceived to be motivated by environmental concern. Bold cells are efficiency behaviors and italic cells are curtailment.

\begin{tabular}{lc}
\hline \multicolumn{1}{c}{ Behavior } & Mean (st. dev.) \\
\hline renewable energy & $\mathbf{4 . 2 1}(\mathbf{1 . 3 9})$ \\
\hline solar & $\mathbf{4 . 1 7 ( 1 . 3 7 )}$ \\
\hline fuel-efficient car & $\mathbf{3 . 6 9 ( 1 . 2 8 )}$ \\
\hline light bulbs & $\mathbf{3 . 3 1}(\mathbf{1 . 3 5})$ \\
\hline bike & $3.29(1.21)$ \\
\hline bus & $3.09(1.28)$ \\
\hline insulate windows & $\mathbf{2 . 7 3 ( 1 . 2 8 )}$ \\
\hline vegetarian diet & $2.63(1.51)$ \\
\hline tire pressure & $\mathbf{2 . 5 1 ( 1 . 3 8 )}$ \\
repair clothes & $2.41(1.49)$ \\
\hline
\end{tabular}


Figure 1. Depiction of materials used in data collection. The left image depicts the board used to determine which behaviors are most motivated by environmental concern. Participants placed behavior cards in the squares of the column that matched their rating. The right image depicts the board used in the Q-sort activity. Participants placed one card in each square to represent the status associated with that behavior.

Perceived motivation activity

(10 behaviors used)

Q-sort activity
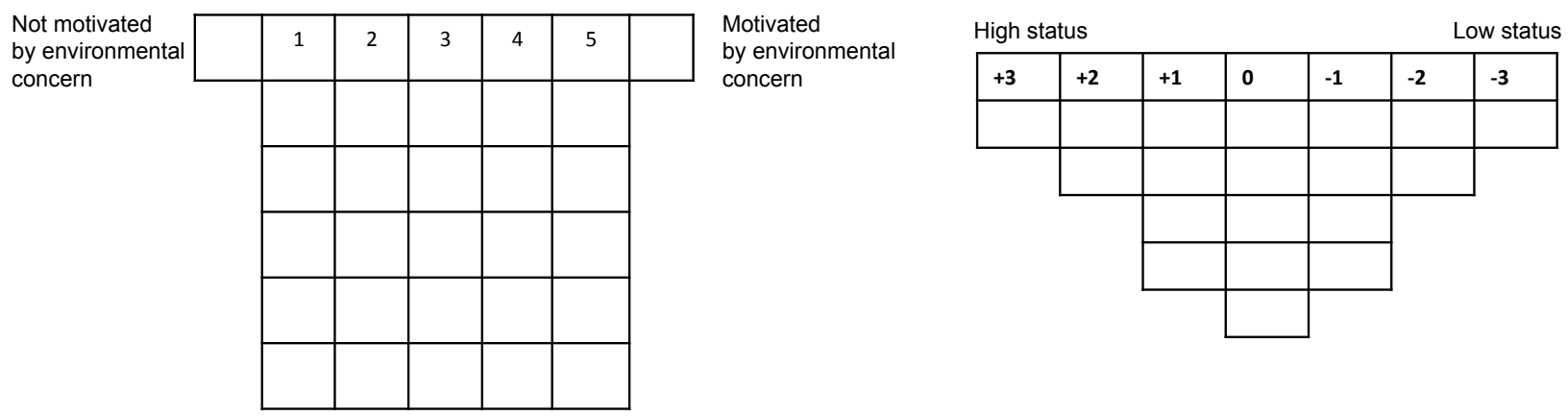